\title{
Fertility Transition in Nigeria: Exploring the Role of Desired Number of Children
}

\author{
By \\ Latifat D.G. Ibisomi \\ African Population and Health Research Center \\ Nairobi, Kenya
}

\begin{abstract}
Reports have suggested the onset of fertility transition in Nigeria and speculations are rife about the factors driving the observed fertility changes. This study investigates if and how 'desired number of children' influences the observed fertility change in the country, utilizing information collected from twenty-four focus group discussion (FGD) sessions conducted across the country. The results show that people are revising the number of children they are having downward, but the desired number of children remains high. Religion and culture are key drivers of current desired number of children but changing socio-economic factors greatly limit the actual number of children people have. The desired number of children does not play noticeable role in the observed fertility transition in Nigeria, posing significant challenges for policies and programmes that aim to lower desired number of children for sustainable fertility level in the country.
\end{abstract}

Key words: Fertility, transition, Nigeria, desired, children

\section{Résumé}

La transition dans la fécondité au Nigéria a commencé et il y a plusieurs hypothèses sur les facteurs responsables du changement observé dans la fécondité. Cette etude examine l'influence du "nombre desiré d'enfants" sur les changements observés dans la fécondité au Nigéria. L'étude utilise des donées collectées pendant des séances de discussion avec vingt-quatre groupes à travers le pays dans le but d'atteindre les objectifs de l'étude. Les résultats montrent que malgrè le fait que le taux de reproduction a baissé, le nombre désiré d'enfants demeure élevé. Ceci est grandement influencé par la religion et la culture alors que les facteurs socio-économiques limitent considérablement le nombre actuel d' enfants que les gens ont. Le nombre désiré d'enfants par les Nigérians demeure élevé et ne joue pas un role notable dans la réduction observée dans la fécondité. L'étude démontre les défis à surmonter par les politiques et programmes qui visent à diminuer le nombre désiré d'enfants à un niveau de fertilité durable dans le pays. 
African Population Studies Vol. $23 N^{\circ} 2 /$ Etude de la Population Africaine Vol. $23 \mathrm{~N}^{* 2}$

\section{Introduction}

The main support for the observed high African fertility has been adduced to the African traditional society and religion, which stressed the importance of ancestry and descent and the separation of cost of childrearing and reproductive decision-making (Caldwell, Orubuloye and Caldwell, 1992; Makinwa-Adebusoye, 2001). This high value that is traditionally placed on children is of great concern because it has sustained the high fertility rate in the region and made it resistant to the forces that brought about fertility decline elsewhere (Caldwell, Orubuloye and Caldwell, 1992; El Badry, 1992; Kalipeni, 1995). Nonetheless, the region has recorded a number of successes by pursuing vigorously programmes of action from the various population and development as well as family planning and reproductive health fora aimed at achieving sustainable fertility patterns worldwide.

Fertility studies in Nigeria have examined a wide range of topics. However, most of these studies are at local geographical units. The studies that have examined the determinants of fertility at the national level are quite old, have been quantitative and are on the proximate determinants of fertility. These are the 1987 Adegbola's study on regional and socio-economic fertility differentials in Nigeria and the Makinwa-Adebusoye and Feyisetan (1994) study on the quantum and tempo of fertility in Nigeria. A recognized important part of the comprehensive framework in the analysis of fertility is the desired number of children (McCarthy and Oni, 1987; Feyisetan and Bankole, 2002; De Rose and Ezeh, 2005). However, no known quantitative or qualitative study have examined its role on fertility level or change in the country. This study intends to fill this gap using qualitative methodology. The use of qualitative methodology for this study is especially important as it explores the role that desired number of children plays in the observed fertility changes in Nigeria from the perspective of the people. It should also provide an insight into the reasons why and how.

\section{Literature Review and Theoretical Framework}

The theoretical approach for this study is derived from a number of fertility theories. Fertility norms, usually reflected by the demand for children and often measured by number of desired children are an essential component of a comprehensive framework for the analysis of fertility determinants (McCarthy and Oni, 1987; Feyisetan and Bankole, 2002; De Rose and Ezeh, 2005). It was proposed that a fertility decline is not very far away when people start conceptualizing their family size (Van de Walle, 1992). This position is similar to the first of the three preconditions for fertility decline proposed by Coale (1973) that fertility must be within the calculus of conscious choice (Makinwa-Adebusoye, 2001; Caldwell, 2001). 
Latifat D.G. Ibisomi: Fertility Transition in Nigeria: Exploring the Role of Desired Number of Children

The theory of demographic transition also posits a future decline in fertility when there is a change in the motivations to have children and fertility desires decline to a much lower level than actual fertility (Van de Walle, 1992; Feyisetan and Bankole, 2002). This was further demonstrated by the Easterlin (1985) framework, which showed how modernization leads to a shift from high to low fertility using the socio-economic approach of demand and supply. The Bongaarts (1993) variant of the demand and supply framework for the analysis of fertility posits that fertility is an outcome of the interaction of supply of births, demand for births and the degree to which people are able to implement their fertility preferences. In essence, the demand for births (children) is one of the key factors that drives eventual fertility outcome.

Studies on demand for births (children) have used different terminologies and definitions such as: desired family size, ideal number of children, fertility preference, desire for additional children and fertility intentions (among others) to describe and or estimate the number of children that people actually want to have. The classic concept is the desired number of children, which is a response to the question "If you could choose the number of children to have in your whole life, how many would that be (irrespective of the number he/ she already have)?"

Although, the measure is said to be prone to rationalization (upward adjustment in stated desired family size so that it is close or equal to actual number of children) and non-numeric bias (under reporting of average family size because some women are unable or unwilling to respond to the question on desired family size) (Bongaarts, 1990), it remains very relevant in the estimation of actual fertility. For various reasons however, peoples' desired family size cannot be precisely attained and as such, it is often different from actual family size. The desired family size is usually lower than the actual family size in pre-transitional societies (typical of developing countries) while the reverse is the case in post-transitional ones (Bacci, 2001).

Fertility studies in Nigeria, have examined a wide range of topics mostly at local geographical areas. These include trends, determinants and differentials of fertility levels; adolescent's reproductive health; family planning; abortion; poverty and fertility dynamics; reproductive intention, reproductive decision-making, spousal influences on reproductive issues, the relationship between child labour and fertility preferences of parents and a host of others.

Fertility change studies in the country have shown that fertility rates started declining since the mid 1970s. Total fertility rates (TFR) declined from 7.0 in 1975 to 6.43 between 1978 and 1982 (Feyisetan and Bankole, 2002). The 1990, 1999 and 2003 estimates are put at 6.01, 5.2 and 5.7, respectively (NDHS, 1990; 1999 and2003; Feyisetan \& Bankole, 2002). It is evident that the TFR has followed a downward trend from the 1970s if one 
ignores the figure given by the 1999 NDHS, which was reported to have been affected by underreporting of births (NDHS, 2003).

Marginal increase in the mean number of children desired has been observed over time in Nigeria. This rose from 4.91 in 1990 to 5.19 by 2003 (Ibisomi, 2007). The observed increase could however have been dictated by the high percentage of non-numeric response in the 1990 survey, which was $57.3 \%$. This declined to $11.0 \%$ by 2003 . The mean desired number of children basically increases as percentage of non-numeric responses decrease over the years. This suggests that the mean desired number of children, which is below the TFR (by available data sets), could perhaps be at par or above the TFRs if non-numeric responses are eliminated.

Given the vital importance of desired number of children in shaping fertility levels and the challenges of obtaining non-bias responses to quantitative survey questions on the indicator, this study uses qualitative methodology to explore the number of children that the Nigerian people desire and the reasons(s) behind the number to assess the role desired number of children plays in the observed fertility changes in Nigeria.

\section{Data and Methods}

This study uses information collected from twenty-four focus group discussion (FGD) sessions conducted across the country. The FGD participants were drawn from Imo, Kano and Oyo States of the South Eastern, Northern and South Western geographical zones of Nigeria respectively. These three zones were selected because they depict the three main ethnic tribes in the country (this how ever does not imply representativeness of all and sundry in the country). The Hausa is in the North, The Ibo in the South East and the Yoruba in the South West.

The FGD sessions were conducted at both rural and urban areas in each of the zones. A small town was used for urban and a typical village as rural in each of the zones. This was to ensure, as much as possible, that it is actually the views of the indigenous population that was sought. The participants in the FGDs were men aged 35 to 59 and women aged 35 to 49 years. Respondents in these age groups were chosen because they are the ones that are more likely to have completed their family size and hence one is able to discern more clearly the relationship between desired and actual number of children. It must be pointed out that using this age group does not in any way impact negatively on the current dynamics of desired number of children in the country. The framing of the relevant questions captures both the past and current thinking and status about the issue. Whereas, using respondents of younger age group would have (at best) captured the present and perhaps the future preferences. Even in the quantitative surveys, responses to the question on ideal family size, is reflective of respondent's 
current situation. People use their current status/experience/wealth/knowledge/p otential and so on to respond to such questions.

The participants were further stratified by level of education as education has been found to be positively associated with fertility levels. It could thus, be equally associated with fertility desires. Overall, eight (4 for men and 4 for women) FGD sessions were conducted in each of the geographical zones and the participants were classified as follows:

1. Urban males, aged between 35 and 59 with less than completed secondary education.

2. Urban males, aged between 35 and 59 with completed secondary or higher education.

3. Urban females, aged between 35 and 49 with less than completed secondary education.

4. Urban females, aged between 35 and 49 with completed secondary or higher education.

5. Rural males, aged between 35 and 59 with less than completed secondary education.

6. Rural males, aged between 35 and 59 with completed secondary or higher education.

7. Rural females, aged between 35 and 49 with less than completed secondary education.

8. Rural females, aged between 35 and 49 with completed secondary or higher education.

Recruitment involved the contact people on the ground going round to identify the people who had the required characteristics and inviting them for the sessions. Discussions were held in the local language most understood by the participants. Each session had between 5 and 8 participants and lasted between one and half and two hours. The sessions were recorded on tapes and notes were also taken by note-takers. The tapes were transcribed verbatim in the local languages, translated into English, typed out and then analysed. A total of eightynine (89) men and eighty-five (85) women participated in the twenty-four (24) focus group discussion sessions. The FGD sessions were conducted between April and July 2006.

In presenting the findings of this study, a description of some of the characteristics of the focus group discussants is provided and then excerpts from the sessions which are basically summaries of discussants' opinions are presented. Effort is also made to represent differences in opinions wherever they occur and direct quotations are made from the discussions to illustrate points made. 


\section{Results}

Basic characteristics of FGD participants.

Table 1 shows that a total of eighty-nine men and eighty-five women took part in the twenty-four focus group discussion sessions. In the South East, the men are two years older and on the average, have 0.4 living children more than the women. In the North and the South West, the ages of the men and women are similar. While the number of living children is also similar between the sexes in the South West, the women in the North have about 1.3 children more than the men. Over half of the men and women from the South East and women from the North have more than four living children.

Table 1. Basic Characteristics of the Focus Group Discussion Participants.

\begin{tabular}{|lcccc|}
\hline \multicolumn{1}{|c}{ FGD groups by region } & Number & $\begin{array}{c}\text { Mean } \\
\text { Age }\end{array}$ & $\begin{array}{c}\text { Mean \# of } \\
\text { children }\end{array}$ & $\begin{array}{c}\text { \# with more } \\
\text { than 4 } \\
\text { children }\end{array}$ \\
\hline South East(Imo State) & 8 & 45.3 & 4.8 & 4 \\
Urban Men (S+) & 8 & 43.6 & 6.6 & 7 \\
Urban Men (S) & 8 & 34.8 & 3.5 & 2 \\
Rural Men (S+) & 8 & 43.8 & 5.6 & 5 \\
Rural Men (S) & 8 & 45.9 & 3.8 & 4 \\
Urban Women (S+) & 8 & 36.3 & 5.0 & 4 \\
Urban Women (S) & 8 & 37.5 & 4.4 & 6 \\
Rural Women (S+) & 8 & 39.5 & 5.8 & 5 \\
Rural Women (S) & 32 & 41.8 & 5.1 & 18 \\
Total sample of Men in region & 32 & 39.8 & 4.7 & 19 \\
Total sample of Women in region & 32.8 & & \\
\hline North (Kano State) & & & 2.8 & 1 \\
Urban Men (S+) & 6 & 37.0 & 1.1 & - \\
Urban Men (S) & 7 & 36.0 & 5.0 & 2 \\
Rural Men (S+) & 6 & 40.5 & 4.7 & 4 \\
Rural Men (S) & 6 & 45.2 & 4.7 & 2 \\
Urban Women (S+) & 6 & 37.8 & 3.8 & 5 \\
Urban Women (S) & 7 & 39.9 & 6.2 & 3 \\
Rural Women (S+) & 6 & 42.0 & 4.7 & 5 \\
Rural Women (S) & 7 & 40.0 & 7.4 & 7 \\
Total sample of Men inegion & 25 & 39.5 & 4.3 & 15 \\
Total sample of Women in region & 26 & 39.9 & 5.6 & \\
\hline
\end{tabular}




\begin{tabular}{|lcccc|}
\hline \multicolumn{1}{|l}{ South West (Oyo State) } & & & & \\
Urban Men (S+) & 8 & 48.0 & 3.4 & 3 \\
Urban Men (S) & 8 & 41.6 & 4.5 & 1 \\
Rural Men (S+) & 8 & 44.0 & 3.1 & - \\
Rural Men (S) & 8 & 32.1 & 2.1 & - \\
Urban Women (S+) & 8 & 45.5 & 3.4 & 3 \\
Urban Women (S) & 8 & 45.0 & 4.1 & - \\
Rural Women (S+) & 5 & 38.6 & 3.4 & 6 \\
Rural Women (S) & 6 & 36.0 & 3.0 & 4 \\
Total sample of Men in region & 32 & 41.4 & 3.3 & \\
Total sample of Women in region & 27 & 42.0 & 3.5 & \\
Total \# of FGD groups: & Men12; & \multicolumn{4}{c}{ Women 12 } \\
Total \# of participants: & Men89; & \multicolumn{4}{c}{ Women- 38 } \\
Total \# with more than 4 children: Men31;
\end{tabular}

Note: $\mathrm{S}+=$ secondary level of education and above; Selow secondary level of education.

\section{Desired number of children.}

In the focus group discussion (FGD) sessions, the first issue initiated was to explore societal expectation as well as individuals' desired number of children. This is a very crucial determinant of eventual fertility outcome as when desires are high, actual child bearing could be high. The question asked was:

"In some communities, people might be expected to have a particular number of children. In some countries, for instance, no more than two children may be seen as desirable for most people. What would you say is the number of children people are expected to have in this community and what are the reasons for this particular number?"

The majority of the discussants do not believe in specifying the number of children they should have and they hinged their position in cultural tradition and religion. They see children as being given by God; hence, no one can basically say how many they want. These ideas are reflected in some of the quotations that follow:

"No one should say that 'I will have only three or four' because God that created us knows the best for us and we should accept what He gives to us whether seven, eight, nine or twelve" (Male, South East, Urban).

"In Islam, a person is not directed to have a certain number of children, so one is given the chance to have as few or as many children as he likes" (Male, North, Urban).

"In the Yoruba community we are expected to have as many as we can and that is why the slogan says, 'you don't count children'. We don't like counting our children" (Male, South West, Urban). 
After voicing their religious and traditional persuasions however, most discussants from the South East mentioned that people should have as few or as many as they could cater for and some go ahead to give numbers. Some discussants from the North also concur with the idea of people having as few or as many children as they can cater for. Some illustrative numbers were also given in the North about some of the people living in the communities while in the South West, a sizeable number of the discussants gave numbers. The 1988 four-child population policy of the government was only referred to in the South West. This could have impacted on the number of children desired by this populace as most of them mentioned four as their desired number. Most of the discussants however attributed the desired number to other reasons. There was not much difference in the views and opinions of discussants by residence, sex or education on this issue. The following are some of the excerpts on this:

"I think there is no number someone has that is enough for the person. It is only required of the person to have that which he can train. I think five is good" (Male, South East, Urban).

"Some people decide on having one, two or three children. After they have gotten the number they want, they stop. But only few of the people in our community have this idea" (Male, North, Urban).

"Four is the laid down ruls but this is political not traditional. Traditionally, one can have as many as possible" (Female, South West, Urban)
Reasons for the desired number of children.

The FGD sessions further explored 'the reasons' for the number of children that people desired. This is necessary to gain an insight into the issues that drive childbearing from the perspective of the discussants and also to be able to identify specific areas that programmes could be targeted (if necessary) for a sustainable fertility level in the country.

The majority of the discussants in the North were first of all of the opinion that the only reason to decide on a certain number of children is ill health of the woman. In general however, most of the discussants from all the regions recognised that the economic situation in the country has changed and that steps have to be taken to be in tune with it. This is illustrated as follows by some of the discussants opinion that follows:

"No specific number except the woman is the type that suffers when giving birth. It is those couples that plan their family" (Female, North, Rural).

"Things have changed. The economy of the country is bad. It is better one has the number one can maintain" (Female, South East, Rural).

"In the North we didn't have that idea, but presently due to economic problems encountered, people are now doing this (i.e. deciding on number of children) because of the problems being faced concerning how to cater for the family" (Male, North, Urban).

"The English say 'cut your coat according to your size'. But nowadays, it is 'cut your coat 
Latifat D.G. Ibisomi: Fertility Transition in Nigeria: Exploring the Role of Desired Number of

according to your cloth'. A truck full of children is a truck full of poverty" (Male, South West, Urban).

In addition to economic consideration, other reasons given for the desired number of children include:

\section{Religion.}

Adherence to one religion or the other is universal in Nigeria and this has a profound influence on the way of life of the people including reproductive issues. Religious beliefs and injunctions came out as one of the reasons for the number of children that people desire. Excerpts on this include:

"The main reason why people want to have many children is because of the prophet's saying that: 'marry and produce a good generation for I shall be proud of your great number on the Day of Judgment'" (Female, North, Rural).

"In the Bible God said marry, increase and multiply" (Male, South East, Urban).

\section{Culture and customs.}

The sessions show that it is customary to have children in all the cultures especially for lineage continuation and securing inheritance. The sentiments attached to having children culturally include the prestige and respect accorded to parents in the community. It also includes some of the roles that the children perform for their parents in the community (such as representation). Some of the discussants are even of the opinion that for someone that has no child, it is better the person was not born because he cannot answer to being a man. Preference for having at least one male child came up in the course of the discussion on lineage continuation as it was said that the girl child leaves the household to take up her husband's family name after marriage thereby depleting her biological household. The importance of this is captured by some of these quotations:

"The Yoruba regard children as legacy. They have as many as possible, so that whenever they pass away, they will have surviving children to take care of their possessions" (Male, South West, Urban).

"The Igbo man believes in numerical strength. One who has many stands the chance of the challenges oflife" (Female, South East, Urban).

"I shall conclude this part of the discussion by saying that whosoever does not have a child throughout his lifetime, then, it is as if God has never created him. Because the moment he dies, everything concerning him dies forever" (Male, North, Rural).

\section{Effective guidance and control of the children.}

From the discussions, this is highly rated by majority of the discussants as they believe that too many children may not be manageable for a couple given the type of living arrangement and the social changes that have taken place in the society where community control of children is fast disappearing. Discussants were aware of the dangers and are scared of the consequences that could emanate from not doing a good job of giving an all round 
training to their children. They were particularly worried about the children turning into social misfits and not leaving a good legacy after their demise. The following are some of the discussants' remarks:

"When you have many children and you're unable to train them, there is no type of character that will not be in that family" (Female, South East, Rural).

"To be able to give them quality care because one wants the children that will survive him to be someone that will have good education and morals. So that by the time the parents are no more, they will leave behind a good legacy" (Male, SouthWest, Urban).

\section{Old age care and provision.}

From the sessions, this is a very important consideration in deciding the number of children. It has long been recognized and cited as one of the reasons for high fertility (Schoumaker, 2004). The majority of the discussants indicated the care that they expect to have from their children in terms of love, company and being there to render any assistance they might require in general. This consideration transcends region, residence, gender and education differentials among the discussants. The following summarizes the views of the discussants on this:

"We have many children because if they grow up they will support us. Presently I am living with my son. My children are the ones taking care of feeding and clothing me since the death of my husband. That is why we are proud of having many children" (Female, North, Urban).

"Nobody knows how God will bless each child. And you don't know who among them will support you later in life" (Male, North, Rural).

"We rely on children for old age. This is not like America where they pack their old people in a place and government is catering for them. The lesser children you have the lesser care that person will have in old age" (Male, South West, Urban).

\section{Family business needs.}

It came out clearly that people consider the preservation of wealth and skills in the family when deciding on the number of children to have. The family's manpower need, to sustain family work or business is also considered. This is particularly so, for people in the North in general and those from rural areas in the South. The people in the North are engaged in both crop farming and livestock rearing while those from the South are mostly engaged in crop farming and at a lesser commercial scale than the people in the North. Some of the quotations from the discussions are given below:

"In this part of the country, people want to have many children because in our own case we only know farming and livestock rearing and the children help us in our day to day activities like farm work and so on" (Male, North, Rural).

"Not having many children in the family makes domestic work to be very dull especially farm work because in Igbo land, we believe in farm work" (Male, South East, Rural). 
Latifat D.G. Ibisomi: Fertility Transition in Nigeria: Exploring the Role of Desired Number of Children

"In this our community, we farm very well. So, we need children to help us on the farms" (Male, SouthWest, Rural).

\section{Death of Child(ren).}

This has long been recognised as a vital determinant in reproductive decision-making (Legrand, Koppenhaver, Mondain and Randall, 2003; Randall and Legrand, 2003). This usually takes the form of insurance effect or child replacement. In the case of insurance, people have more than needed with the hope that even if some die, some will be left while for child replacement, another child is born when one dies. Child mortality effect is built into the decision-making of this populace (especially those from the South West) mainly through the form of insurance. Below are some of the opinions of the discussants on this issue.

"The reason why I said six is because, some may die. You don't wait for that to happen before you take action. It is better to insure against it" (Male, SouthWest, Rural).

"Supposing some of the children die, what does one do? That is why one should have more than four" (Female, SouthWest, Rural).

Other reasons given for the desired number of children are that: the children may act as support to each other later in life; some parents, especially those that have only one child prevail on their children to have many children; and that some people have few number of children because they fear that they might die early and leave behind many little children in hardship. This section concludes with a remark by one of the discussants thus:

"There will always be problems whether the family size is small or large" (Male, South East, Rural).

\section{Discussion}

Although, people were reluctant to state the number of children that they desired in the FGD sessions, it came out from the discussions that this is basically because it was seen as an affront to God to state the number that they want. This could be an explanation to non-numeric responses given by respondents when asked questions on desired or ideal number of children and not necessarily because they do not know what they want or not aware of the concept of family size and the possibility of influencing it.

It was evident from the focus group discussion sessions that people desire high number of children and that they have been revising the number of children they are having downward due to the 'supposed' economic hardship in the country, which has put a constraint on giving quality education, training and care to a large number of children. This result was also reported by Caldwell (1997) on the effect of economic forces in hastening the onset of fertility decline.

In the discussion sessions, there was no consensus as to a specific number of children that people should have except in the South West where majority of the respondents mentioned four (This may be 
related to the influence of the 1988 population policy, which specifically targeted reducing the number of children a woman is likely to have during her lifetime to four by the year 2000 . This also drives the policies on provision/benefits for children of employees of most employers at the work place). The majority of the discussants are however of the opinion that people should behave responsibly by having the number that they can comfortably manage and cater for.

On the reasons for the number of children desired, the focus group discussions brought out the fact that peoples' desires are strongly influenced by their perception of the value attached to children as well as the costs and potential benefits of children. For example, among the Yoruba of South West Nigeria as in most ethnic groups in Nigeria, children validate marriage (Makinwa-Adebusoye and Feyisetan, 1994). Children also confer a special status on women who may be honoured for their role in perpetuating the lineage. Some Igbo communities also honour women who have successfully borne ten or more children. This parity ten custom bestows on a woman a special honour as a member of a privileged class (Odimegwu, 1998; Edewor, 2001).

The costs of children were well articulated in the discussants' concern of the economic situation in the country, which limits the number that they would have loved to have. This consideration in addition to the potential social, cultural, religious, future economic benefit and care to parents among other reasons moderate the fertility aspirations of the people in their eventual fertility behaviour. All things being equal, the desired family size should be greater than the actual family size in Nigeria a situation thought to be the preserve of the developed nations.

A possible limitation of this study is that the discussions could have been more of social responses rather than practical, as discussants might want to be seen as socially correct by their peers in the group. Thus, the individual experiences may not be represented here. The community expectations and practices are however comprehensively highlighted. This is evident in the fact that no difference worthy of mention was found in the views of discussants by gender, education, zone or residence. This shows that the responses are a product of operating social norms that are shared by virtually all and with high probability of continued transmission. This limitation does not impact negatively on this study as it seeks to explore the number of children desired by the people within the societal context.

\section{Conclusion}

The focus group discussion sessions show that the leaning of the majority of the Nigerian people towards smaller family size could be reversed with improvement in the standard of living and liquidity in the country's economy. This conclusion is informed by the fact that discussants clearly show that the large family size promoted by both culture and 
Latifat D.G. Ibisomi: Fertility Transition in Nigeria: Exploring the Role of Desired Number of Children

religion is mainly curtailed by the apparent economic downturn in the country. This was aptly captured by the following quote from one of the discussants:

"It is the kind of job that one is doing that determines the number of children that one is going to have. If I have enough money, I will have many children even more than ten. But I will not be able to cater for them because the kind of job that I am doing does not permit me to have more than four" (Male, South West, Urban).

The number of children desired by the Nigerian people is still high and from the findings of this study, the fertility transition in the country is driven by other considerations apart from the peoples' desired number of children. Thus, the number of children desired by the Nigerian people in general does not seem to play a key reducing role in the observed fertility changes in the country.

There are important policy and program implications for the findings of this study. The decline in family size is largely driven by economic constraint rather than any noble concern for fertility norms or expectations. This suggests that a reversal of the declining fertility trend could occur if or when the country becomes prosperous and general living standards improve thereby. Increase in fertility as a result of prosperity has been documented before in the country in the period between 1965 and the mid 1970s when there was an increase in workers salary as a result of the rise in revenue from oil export (Oladosu, 2001; Feyisetan and Bankole, 2002).

In view of the issues highlighted above, it is recommended that:

(1) Strategies to implement the population policies targeting fertility reduction in the country be expanded and improved upon. For example, the 1988 population policy has as one of its objectives 'to provide to everyone the necessary information and education on the value of reasonable family size to both the individual family and the future of the nation in achieving self reliance' (Federal Government of Nigeria, 1988). If this is implemented by programmes and adopted by the Nigerian people irrespective of their socioeconomic status, it could lead to a lowering of the number of children that people desire for a sustainable fertility level in the country.

(2) The government designs other equally motivating strategies of rewarding workers (such as scholarships for top performing children of workers) other than monetary (cash). Pension schemes should also be improved upon and ways of expanding it to all sectors of the population explored. This should assist in diluting the effect of old age economic reliance on children thereby contributing to lower desire for children and eventual fertility decline in the country. 


\section{REFERENCES}

Bacci, M.L. 2001. Comment: Desired Family Size and the Future Course of Fertility. Population and Development Review 27, Supplement: Global fertility Transition: 282-289.

Bongaarts, J. 1990. The Measurement of Wanted Fertility. Population and Development Review 6, (3): 487-506.

Bongaarts, J. 1993. The Supply-Demand Framework for the Determinants of Fertility: An Alternative Implementation. Population Studies 47, (3): 437-456.

Caldwell, J.C. 1997. The Global Fertility Transition: The Need for a Unifying Theory. Population and Development Review 23, (4): 803-812.

Caldwell, J.C. 2001. Globalization of Fertility Behaviour. Population and Development Review 27, Supplement: Global Fertility Transition. Page 93-115.

Caldwell, J.C; Orubuloye, I.O. and Caldwell, P. 1992. Fertility Decline in Africa: A New Type of Transition? Population and Development Review 8, (2): 211-242.

DeRose, L.F. and Ezeh, A.C. 2005. Men's Influence on the onset and Progress of Fertility Decline in Ghana, 198898. Population Studies 59, (2): 197210.
Easterlin RA. and Crimmins EM; 1985. The Fertility Revolution. The University of Chicago Press.

Edewor, P.A. 2001. Fertility and the Value of Children Among the Isoko of Delta State, Nigeria. A thesis in the Department of Sociology submitted to the faculty of Social Sciences in partial fulfillment for the award of the degree of Doctor of Philosophy, University of Ibadan, Ibadan, Nigeria.

El-Badry, M.A. 1992. Emerging Population Issues in Africa. International Statistical Review 60, (2):119-127.

Federal Government of Nigeria. 1988. National Policy on Population for Development, Unity, Progress and Self-reliance.

Federal Office of Statistics [Nigeria] and IRD/Macro International Inc. 1992. Nigeria Demographic and Health Survey 1990.

Feyisetan, B.J. and Bankole, A. 2002. Fertility Transition in Nigeria: Trends and Prospects. Www.un.org/esa/population/pu blications/completingfertility/Re visedBANKOLEpaper.PDF.

Ibisomi, L.D.G. 2007. Analysis of Fertility Dynamics in Nigeria: Exploration into Fertility Preference Implementation. A Research Thesis Submitted to the Faculty of Humanities, University of the 
Latifat D.G. Ibisomi: Fertility Transition in Nigeria: Exploring the Role of Desired Number of Children

Witwatersrand, Johannesburg, in fulfilment of the Requirements for the Award of the Degree of Doctor of Philosophy in Demography and Population Studies.

Kalipeni, E. 1995. The Fertility Transition in Africa. Geographic Review 85, (3): 286-300.

Legrand, T; Koppenhaver, T; Mondain, N and Randall, S. 2003. Reassessing the Insurance Effect: A Qualitative Analysis of Fertility Behaviour in Senegal and Zimbabwe. Population and Development Review 29, (3): 375403.

Makinwa-Adebusoye, P. 2001. Sociocultural Factors Affecting Fertility in Sub-Sahara Africa. Workshop on Prospects for Fertility Decline in High Fertility Countries. Population Division, Department of Economic and Social Affairs, United Nations Secretariat. New York, 9-11 July 2001. UN/POP/PFD/2001/12.

Makinwa-Adebusoye, P.K. and Feyisetan, B.J. 1994. The quantum and Tempo of Fertility in Nigeria. In Fertility Trends and Determinants in Six African Countries. DHS Regional Analysis Workshop for Anglophone Africa. Macro International Inc. Calverton, Maryland.

McCarthy, J and Oni, G.A. 1987. Desired Family Size and Its Determinants
Among Urban Nigerian Women: A Two-Stage Analysis. Demography 24, (2): 279-290.

National Population Commission (Nigeria), 2000. Nigeria Demographic and Health Survey 1999. Calverton, Maryland: National Population Commission and ORC/Macro.

National Population Commission (Nigeria), 2004 . Nigeria Demographic and Health Survey 2003. Calverton, Maryland: National Population Commission and ORC/Macro.

Odimegwu, C.O. 1998. Application of Demographic Models to Fertility in a Nigerian Ethnic Group: Implications for Population Growth and Family Planning Programmes. Development and Society 27, (2).

Oladosu, M. 2001. Prospects for Fertility Decline in Nigeria: Comparative Analysis of the 1990 and 1999 NDHS Data. Workshop on Prospects for Fertility Decline in High Fertility Countries. Population Division, Department of Economic and Social Affairs, United Nations Secretariat. New York, 9-11 July 2001 . $\mathrm{UN} / \mathrm{POP} / \mathrm{PFD} / 2001 / 12$.

Randall, S. and Legarnd, T. 2003. Reproductive Strategies and Decision in Senegal: The Role of 
African Population Studies Vol. $23 N^{\circ}$ 2/Etude de la Population Africaine Vol. $23 N^{*} 2$

Child Mortality. Population (English Edition) 58, (6): 687-716.

Schoumaker, B. 2004. Poverty and Fertility in Sub-Saharan Africa: Evidence f r o m 25 Countries. Http://paa2004.princeton.edu/d ownload.asp?submissionId $=40032$

Van de Walle, E. 1992. Fertility Transition, Conscious Choice and Numeracy. Demography 29, (4): 487-502. 